\title{
Lidocaine with fentanyl, compared to morphine, marginally improves postoperative epidural analge- sia in children
}

\author{
[Une combinaison de lidocä̈ne et de fentanyl, comparée à la morphine, améliore \\ peu l'analgésie péridurale postopératoire chez les enfants]
}

Francisco Reinoso-Barbero MD PhD, * Barbara Saavedra MD, * Sara Hervilla, * Jesús de Vicente MD, * Beatriz Tabarés MD, † María S. Gómez-Criado MD†

\begin{abstract}
Purpose: To compare the epidural administration of fentanyl ( I $\mu \mathrm{g} \cdot \mathrm{mL}^{-1}$ ) combined with lidocaine $0.4 \%$ to preservative- free morphine for postoperative analgesia and side effects in children undergoing major orthopedic surgery.

Methods: In a prospective, double-blind study, 30 children, ASA I-II, 2-16-yr-old, were randomly allocated to receive immediately after surgery either epidural F-L (epidural infusion at a rate of $0.1-0.35 \mathrm{~mL} \cdot \mathrm{kg}^{-1} \cdot \mathrm{hr}^{-1}$ of I $\mu \mathrm{g} \cdot \mathrm{mL}^{-1}$ of fentanyl and lidocaine $0.4 \%$ ) or epidural M (bolus of $20 \mu \mathrm{g}^{\mathrm{kg}}{ }^{-1}$ of morphine in $0.5 \mathrm{~mL} \cdot \mathrm{kg}^{-1}$ saline every eight hours). Both groups received $40 \mathrm{mg} \cdot \mathrm{kg}^{-1}$ of iv metamizol (dipyrone) every six hours. In the F-L Group, blood samples were taken on the second and third postoperative day to determine total lidocaine concentrations. Adequacy of analgesia using adapted pediatric pain scales (0-10 score) and side-effects were assessed every eight hours postoperatively.

Results: Resting pain scores were under 4, 95\% of the time in the F-L Group and $87 \%$ of the time in the M Group (Chi square $=4.674, P<0.05)$. The frequency of complications was very similar in both groups. The F-L Group total plasma lidocaine concentrations were directly related to the dose received, and below the toxic range in all patients.

Conclusions: Postoperative epidural fentanyl with lidocaine infusion provides slightly better analgesia than conventional bolus administration of epidural morphine. Side-effects or risk of systemic toxicity were not augmented by the addition of lidocaine to epidural opioids.
\end{abstract}

Objectif : Comparer l'administration péridurale de I $\mu \mathrm{g} \cdot \mathrm{mL}^{-1}$ de fentanyl combiné à de la lidocaïne à 0,4\% (FL), à de la morphine (M) sans agent de conservation, quant à la qualité de l'analgésie postopératoire et aux effets secondaires chez des enfants qui doivent subir une importante opération orthopédique.

Méthode : C'est une étude prospective et à double insu auprès de 30 enfants, d'état physique ASA I-II, de 2 à 16 ans et répartis au hasard qui ont reçu immédiatement après l'opération, soit une combinaison $F-L$ péridurale (perfusion péridurale à $0,1-0,35 \mathrm{~mL} \cdot \mathrm{kg}^{-1} \cdot \mathrm{h}^{-1}$ de 1 $\mu \mathrm{g} \cdot \mathrm{mL}^{-1}$ de fentanyl et de lidocaïne à $0,4 \%$ ), soit de la $\mathrm{M}$ péridurale (bolus de $20 \mu \mathrm{g} \cdot \mathrm{kg}^{-1}$ de morphine dans $0,5 \mathrm{~mL} \cdot \mathrm{kg}^{-1}$ de solution salée, toutes les huit heures). Tous ont reçu $40 \mathrm{mg} \cdot \mathrm{kg}^{-1}$ de métamizol (dipyrone) iv toutes les six heures. Dans le groupe F-L, les échantillons sanguins ont été prélevés le deuxième et le troisième jour postopératoire pour déterminer les concentrations totales de lidocaïne. La qualité de l'analgésie postopératoire a été évaluée, grâce à des échelles de douleur adaptées aux enfants (score de 0-10), de même les effets secondaires, toutes les huit heures.

Résultats : Les scores de douleur au repos ont été inférieurs à 4, 95 $\%$ du temps chez les enfants du groupe $F$ - $L$ et $87 \%$ du temps chez ceux du groupe $M$ (Chi carré $=4,674 ; P<0,05)$. La fréquence des complications a été très semblable dans les deux groupes. Les concentrations plasmatiques de lidocaine du groupe $F$ - $L$ étaient en relation directe avec la dose reçue et sous les valeurs toxiques, chez tous les enfants.

Conclusion : La perfusion péridurale postopératoire de fentanyl, combinée à la lidocaïne, fournit une analgésie légèrement meilleure que l'administration péridurale traditionnelle d'un bolus de morphine. Les effets secondaires ou le risque de toxicité généralisée n'augmentent pas avec l'ajout de lidocaïne aux opiö̈des périduraux.

From the Departamentos de Anestesiología* y Farmacología† Clínica, Hospital Universitario "La Paz”, Facultad de Medicina, Universidad Autónoma de Madrid, Madrid, Spain

Address correspondence to: Dr. Francisco Reinoso-Barbero, Coordinador Médico de la Unidad de Dolor Infantil, Departamento de Anestesiología, Hospital Infantil "La Paz", Paseo de la Castellana 261, 28046 Madrid. Phone: +349 1727 7315; Fax: +349 1727 7033 ;

E-mail: FREINOSO@santandersupernet.com

Accepted for publication May 7, 2001.

Revision accepted September 26, 2001. 
$\mathrm{E}$ PIDURAL opioid administration during the postoperative period provides good analgesia while decreasing the risks and adverse side-effects usually associated with parenteral opioid drug administration. ${ }^{1}$ Epidural opioid analgesia has been proven effective in children, although some specific precautions should be taken because morphine can produce serious respiratory depression. ${ }^{2}$

Local anesthetic drugs can be added safely to opioids for postoperative analgesia. ${ }^{3}$ The most common agents for postoperative epidural analgesia are bupivacaine and ropivacaine. ${ }^{4}$ Although lidocaine is chemically related to these amide local anesthetics and has been extensively used in pediatric patients, ${ }^{5}$ we are unaware of published clinical experience using lidocaine as a local anesthetic agent in postoperative epidural analgesia.

The aim of this study was to evaluate the efficacy and safety of a mixture of lidocaine $(0.4 \%)$ plus 1 $\mu \mathrm{g} \cdot \mathrm{mL}^{-1}$ of fentanyl used as a continuous postoperative epidural analgesia in a pediatric population that had undergone major orthopedic surgery when compared to our standard practice of administering epidural boluses of morphine $\left(20 \mu \mathrm{g} \cdot \mathrm{kg}^{-1}\right)$.

Methods

After Institutional approval, 30 children (ASA I and II, aged 2-16 yr) who were scheduled for vertebral arthrodesis, vascularized bone graft, amputation or osteotomy were studied. Written informed parental consent was obtained. The study was prospective, randomized and double-blinded. Children with coagulopathy, neurological deficit, neuromuscular disease, systemic infection or allergy to morphine, fentanyl or lidocaine were excluded.

Following induction of anesthesia the child was placed in the lateral position and, using the loss of resistance technique, the epidural space was detected at the L4-L5 interspace. A 19 or 20-gauge epidural catheter was introduced via an 18 or 19-gauge Tuohy needle. Depending on location of surgery the patients received $0.1-0.5 \mathrm{~mL} \cdot \mathrm{kg}^{-1}$ of bupivacaine $0.25 \%$ with epinephrine. The maximum bolus was $20 \mathrm{~mL}$.

Epidural drug administration was initiated on the postoperative ward, using a standardized continuous epidural infusion of lidocaine $0.4 \%$ with fentanyl 1 $\mu \mathrm{g} \cdot \mathrm{mL}^{-1}$ at an initial rate similar to the successful intraoperative epidural volume employed per hour with an initial bolus of $0.5 \mathrm{~mL} \cdot \mathrm{kg}^{-1}$ of saline every eight hours in the F-L Group.

The $M$ Group received a standardized continuous epidural infusion of saline at an initial rate similar to the successful intraoperative epidural volume
TABLE I Patient demographic data

\begin{tabular}{llll}
\hline & Fentanyl-lidocaine Group & Morphine Group & $P$ \\
\hline Age $(\mathrm{yr})^{*}$ & $10.1 \pm 1.3$ & $11.1 \pm 3.2$ & 0.487 \\
Sex (F/M) & $6 / 9$ & $6 / 9$ & 0.95 \\
Weight* $^{*}$ & $41.4 \pm 14.2$ & $37.7 \pm 10.7$ & 0.428 \\
\hline
\end{tabular}

*Data are expressed as means \pm standard deviation.

TABLE II Types of surgery

\begin{tabular}{lll}
\hline & $\begin{array}{l}\text { Fentanyl-lidocaine } \\
\text { Group }\end{array}$ & $\begin{array}{l}\text { Morphine } \\
\text { Group }\end{array}$ \\
\hline Vascularized bone graft & 4 & 3 \\
Vertebral arthrodesis & 5 & 8 \\
Osteotomy & 3 & 2 \\
Periosteal resection & 2 & 2 \\
Amputation & 1 & 0 \\
Total & 15 & 15 \\
\hline
\end{tabular}

Data are expressed as number of cases.

TABLE III Incidence of side-effects

\begin{tabular}{llll}
\hline & $\begin{array}{l}\text { Fentanyl-lidocaine } \\
\text { Group }\end{array}$ & $\begin{array}{l}\text { Morphine } \\
\text { Group }\end{array}$ & $P$ \\
\hline Motor weakness & $1(6 \%)$ & $0(0 \%)$ & 0.3 \\
Pruritus & $0(0 \%)$ & $1(6 \%)$ & 0.3 \\
Nausea-vomiting & $5(33 \%)$ & $7(46 \%)$ & 0.3 \\
Respiratory depression & $0(0 \%)$ & $0(0 \%)$ & 0.95 \\
\hline
\end{tabular}

Data are number of children (\%).

employed per hour with an initial bolus of 0.5 $\mathrm{mL} \cdot \mathrm{kg}^{-1}$ of morphine in saline $\left(40 \mu \mathrm{g} \cdot \mathrm{mL}^{-1}\right)$. Epidural drugs were prepared by nurses who did participate in the evaluation of the children.

All the children who had epidural catheters were cared for in one of several, appropriately staffed, designated wards. Postoperative pain control was standardised and included routine recording of heart rate, blood pressure, respiratory rate and pulse oxymetry, pain score, and incidence of nausea or vomiting and pruritus every eight hours. ${ }^{6}$ Analgesia was scored in all cases from 0 to 10 . Children who were older than six years or were cooperative scored their pain on a visual analogue scale $(0$ corresponded to no pain and 10 to the worst imaginable pain). Children under six years or who could not express themselves, were observed according to the parameters of the "LLANTO" scale, ${ }^{7}$ an adapted and validated Spanish objective pain scale (in which scores also range from 0 to 10 ). In both groups, if pain scores were not below 2 , the rate of continuous epidural infusion was augmented in $0.05 \mathrm{~mL} \cdot \mathrm{kg} \cdot \mathrm{hr}^{-1}$ increments simultaneous to the augmentation in the volume 


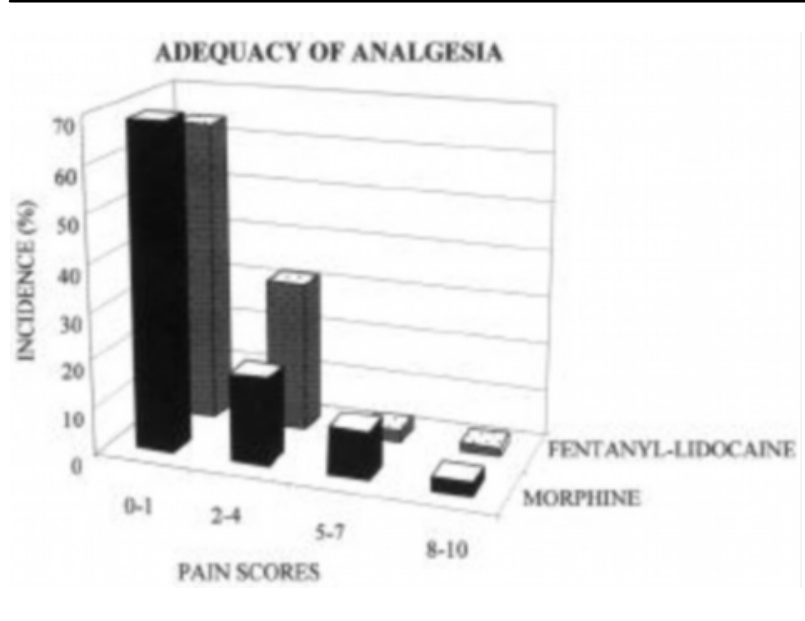

FIGURE 1 Visual analogue scale (0-10) or LLANTO observational scale $(0-10)$ were used to determine the adquacy of analgesia postoperatively.

of epidural boluses in $0.05 \mathrm{~mL} \cdot \mathrm{kg}^{-1}$ increments. The maximum increases permitted were up to 0.35 $\mathrm{mL} \cdot \mathrm{kg} \cdot \mathrm{hr}^{-1}$ of continuous infusion and $0.75 \mathrm{~mL} \cdot \mathrm{kg}^{-1}$ every eight hours of bolus administration. If any pain score had remained $>5$, iv fentanyl would have been prescribed, the epidural infusion discontinued and the patient would have been excluded from the study. IV metamizol (dypirone - see discussion) $\left(40 \mathrm{mg} \cdot \mathrm{kg}^{-1}\right)$ was administered regularly every six hours in both groups.

The volume of epidural infusion per hour and the volume of epidural boluses administered were recorded. The times of initiation and discontinuation of the epidural analgesia were documented. The mean epidural infusion rate and mean dose of epidural morphine were calculated in each group.

Two millilitres of blood were extracted on the morning of the second and third postoperative days to determine the total plasma lidocaine concentration. The blood was centrifuged and stored at $-20^{\circ} \mathrm{C}$ until analysis.

Demographic and parametric data were expressed as mean \pm standard deviation. Parametric data were analyzed using the paired ANOVA test. Non-parametric data were analyzed using Chi square. $P<0.05$ was accepted as statistically significant.

Results

Thirty children (aged 2-16 yr) scheduled for elective major orthopedic surgery were studied. Fifteen children received epidural F-L and 15 lumbar epidural $M$.

Demographic data did not differ between groups (Table I). The type of surgery performed on the children in the study is listed in Table II.

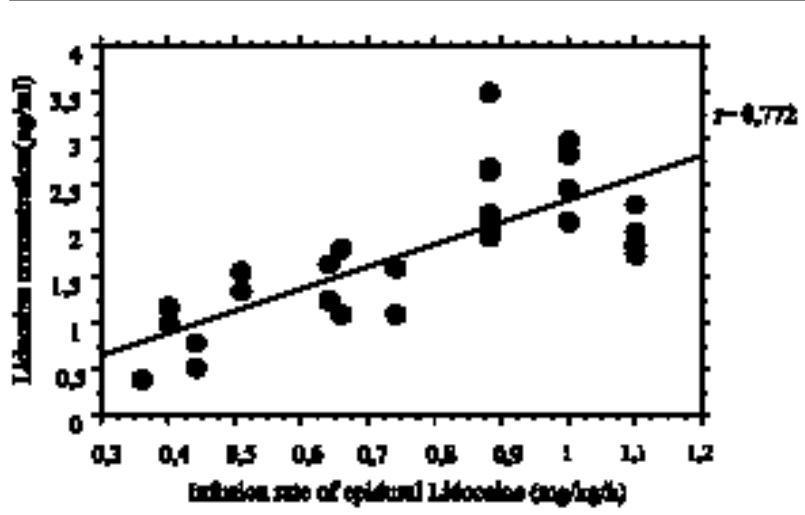

FIGURE 2 Serum lidocaine levels in 14 patients as a function of the rate of perfusion.

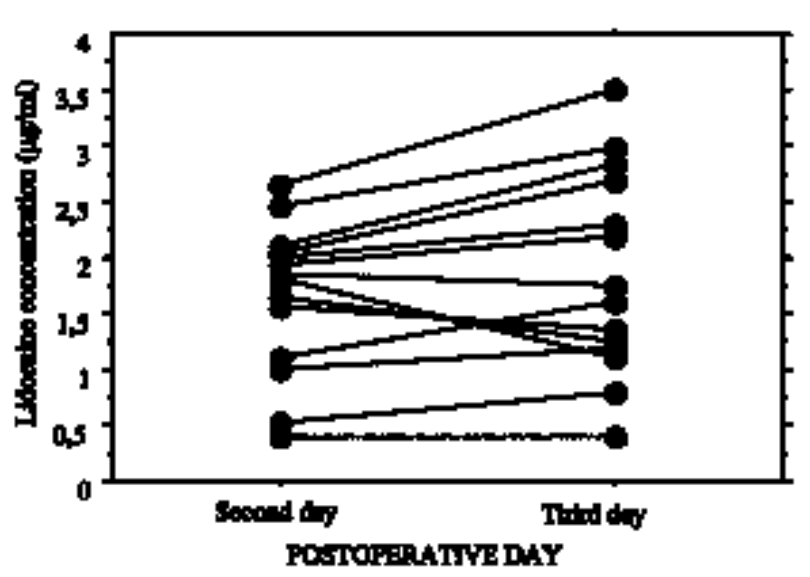

FIGURE 3 Repeat lidocaine concentrations in 14 patients on the second and third postoperative day.

Clinical analysis of the recorded data indicated that the mean perfusion rate for the epidural analgesic solution was $0.19 \mathrm{~mL} \cdot \mathrm{kg}^{-1} \cdot \mathrm{hr}^{-1}$ (range $0.1-0.35$ $\mathrm{mL} \cdot \mathrm{kg}^{-1} \cdot \mathrm{hr}^{-1}$ ) for the F-L Group and the mean dose of morphine administered per bolus was $23.6 \mu \mathrm{g} \cdot \mathrm{kg}^{-1}$ (range 20-30 $\mu \mathrm{g}$ ) in the M Group.

Nursing staff recorded pain level a total of 108 times in the F-L Group and on 108 occasions also in the $M$ Group patients (Figure 1). Pain control was considered satisfactory when pain scores were below 4. Satisfactory pain control was more frequent in the L-F Group (95\% occasions) than in M Group (87\%; Chi square $=4.674, P<0.05)$. 
Complications and adverse side-effects were very similar with both epidural analgesic regimens and were also recorded by frequency (Table III).

Lidocaine plasma levels ranged between 0.4 and $3.8 \mu \mathrm{g} \cdot \mathrm{mL}^{-1}$ and were determined on 28 occasions. In one patient, it was impossible to obtain blood samples because the arterial catheter was prematurely displaced and no routine analyses were required. The level of serum lidocaine achieved was strongly related with the dose employed (regression coefficient of dose vs serum level of $\mathrm{r}=0.772 ; \mathrm{F}_{1,26}=38.377, P<0.0001$; Figure 2). Nevertheless, comparison of blood lidocaine levels on the second and third postoperative days showed no significant variations in the mean plasmatic concentrations of lidocaine $\left(1.65 \pm 0.67 \mu \mathrm{g} \cdot \mathrm{mL}^{-1}\right.$ vs $1.85 \pm 0.91 \mu \mathrm{g} \cdot \mathrm{mL}^{-1}, \mathrm{~F}_{1,26}=0.435, P=0.51$; Figure 3$)$. No signs or symptoms of neurological or cardiovascular toxicity attributable to lidocaine were observed.

Discussion

Epidural analgesia is widely employed for treatment of pediatric postoperative pain. ${ }^{8}$ The analgesic efficacy achieved in the L-F Group was very satisfactory, since nine out of ten observations for pain during the immediate postoperative period found no pain or only slight pain. However, the difference between 95\% (L-F Group) and 87\% (M Group) of satisfactory pain control, despite its statistical significance, is not that clinically striking considering the small numbers and the variety of surgical procedures involved. Additionally, we cannot eliminate the possibility that differences in the quality of analgesia were the result of different administration regimens, i.e., intermittent $v s$ continuous. ${ }^{9}$ The use of patient-controlled epidural analgesia (PCEA) or nurse-parent controlled epidural analgesia (NPCEA) techniques, in which the child or the child's caretaker administer additional boluses of epidural analgesia depending on clinical requirements, could have prevented the incidence of intense postoperative pain (scores $>4$ ) more effectively. It is interesting to note that a very low concentration of lidocaine $(0.4 \%)$ combined with a low concentration of fentanyl $\left(1 \mu \mathrm{g} \cdot \mathrm{mL}^{-1}\right)$ provided very effective analgesia, despite the low doses employed $\left(0.4-1.4 \mathrm{mg} \cdot \mathrm{kg}^{-1} \cdot \mathrm{hr}^{-1}\right.$ of lidocaine or $0.1-0.35 \mu \mathrm{g} \cdot \mathrm{kg}^{-1} \cdot \mathrm{hr}^{-1}$ of fentanyl) and probably reflects the characteristic synergy provided by the concomitant administration of epidural opiates and lidocaine. ${ }^{10}$ Furthermore, lidocaine probably has some additional intrinsic analgesic property due to its capacity to prevent spinal hypersensibilization and "wind up" phenomena caused by blocked sodium channels. ${ }^{1}$ 1

The frequency of adverse side-effects, such as nausea and vomiting or pruritus, observed in the F-L
Group, was similar to that found when employing our usual postoperative analgesic epidural morphine doses. ${ }^{12}$ The addition of systemic doses of a drug like metamizol with a well-established analgesic activity that, like ketorolac, inhibits prostaglandine synthesis, but has a different safety profile, probably allowed decreased doses of epidural drugs and, in this way, decreased the incidence of adverse effects. ${ }^{13}$

The incidence of lower limb weakness (Table III) observed in our study during lidocaine infusion was lower than in other series. ${ }^{14}$ Only one child presented severe motor blockade (equivalent to levels 3 and 4 on the Bromage scale), and it is possible that mild motor blockade was not observed in very young or uncooperative patients. However, almost all LF Group patients were able to walk and move almost in the same way as those in the M Group. Thus, despite its capacity to produce a very strong motor block at high concentrations, lidocaine maintains its analgesic properties and does not present this adverse effect when used in low concentrations and in combination with epidural fentanyl and $i v$ metamizol.

The clinical toxicity of lidocaine depends on plasma levels. ${ }^{15}$ Substantial inter-individual variations in plasmatic lidocaine concentrations were recorded in our patients, but in no sample did this measurement even approach toxic levels (Figures 2 and 3). The highest lidocaine plasma level observed in our study was 3.8 $\mu \mathrm{g} \cdot \mathrm{mL}^{-1}$, while the average was $1.7 \mu \mathrm{g} \cdot \mathrm{mL}^{-1}$. This concentration has been associated with beneficial effects like anti-arrhythmia and positive inotropism.

Continuous epidural infusion of lidocaine in pediatric patients did not have any significant cumulative effect on plasma concentrations in this study; on the other hand, bupivacaine, another common local anesthetic, has a demonstrated potential for systemic toxicity in very young patients. ${ }^{16}$

In the future, double-blind prospective and randomized studies comparing different local anesthetic agents (bupivacaine $v s$ lidocaine $v s$ ropivacaine) or different analgesic techniques (continuous perfusion vs NPCA-PCA) will help us to identify the ideal analgesic agents and the best method of administration in this patient population.

In summary, the use of a continuous epidural infusion of lidocaine $(0.4 \%)$ and fentanyl $\left(1 \mu \mathrm{g} \cdot \mathrm{mL}^{-1}\right)$, in combination with $i v$ metamizol $\left(40 \mathrm{mg} \cdot \mathrm{kg}^{-1}\right)$ provided slightly better pain control than our usual regimen of epidural morphine ( $\left.20 \mu \mathrm{g} \cdot \mathrm{kg}^{-1} \mathrm{q} 8 \mathrm{hr}\right)$, also in combination with iv metamizol $\left(40 \mathrm{mg} \cdot \mathrm{kg}^{-1}\right)$ during the first three postoperative days in healthy children (2-16 $\mathrm{yr}$ of age) undergoing orthopedic surgery without increasing the incidence of adverse side-effects or systemic toxicity. 
Acknowledgements

Ricardo Tuset died in March 1999 after a short illness. The authors would like to acknowledge his enormous contribution to the Acute Pain Service at the Hospital Infantil "La Paz" and his excellent teaching in Pediatric Anesthesia. The authors would like to thank the physicians and nurses of the Service of Anesthesia for their help in completing the study.

\section{References}

l Anzai $\Upsilon$, Nishikawa T. Thoracic epidural clonidine and morphine for postoperative pain relief. Can J Anaesth 1995; 42: 292-7.

2 Karl HW, Tyler DC, Krane EJ. Respiratory depression after low-dose caudal morphine. Can J Anaesth 1996; 43: 1065-7.

3 Wulf $H$, Winckler K, Maier CH, Heinzow B. Pharmacokinetics and protein binding of bupivacaine in postoperative epidural analgesia. Acta Anaesthesiol Scand $1988 ; 32: 530-4$.

4 Scott DA, Emanuelsson B-M, Mooney PH, Cook RJ, Junestrand $C$ Pharmacokinetics and efficacy of longterm epidural ropivacaine infusion for postoperative analgesia. Anesth Analg 1997; 85: 1322-30.

5 Stayer SA, Pasquariello CA, Schwartz RE, Balsara RK, Lear $B R$. The safety of continuous pleural lignocaine after thoracotomy in children and adolescents. Paediatr Anaesth 1995; 5: 307-10.

6 Brenn BR, Rose JB. Pediatric pain services: monitoring for epidural analgesia in the non-intensive care unit setting. Anesthesiology. 1995; 83: 432-3.

7 Herreras JL, Reinoso-Barbero F, Pérez-Scharnowska H, Alonso FJ, Hervilla S, Borges JJ. Escala "Llanto": nueva escala de medida de dolor agudo en pediatría. Rev Esp Anestesiol Reanim 1999; 46: 160-1.

8 Carr AS, Fear DW, Sikich N, Bissonnette B. Bupivacaine $0.125 \%$ produces motor block and weakness with fentanyl epidural analgesia in children. Can J Anaesth 1998; 45: 1054-60.

9 Yaster M, Tobin JR, Billett C, Casella JF, Dover G Epidural analgesia in the management of severe vasoocclusive sickle cell crisis. Pediatrics 1994; 93: 310-5.

10 Wajima $Z$, Shitara T, Ishikawa $G$, Kaneko $K$, Inoue $T$, Ogawa $R$ Analgesia after upper abdominal surgery using extradural administration of a fixed dose of buprenorphine in combination with lignocaine given at two infusion rates: a comparative study. Acta Anaesthesiol Scand. 1997; 41: 1061-5.

11 Wallace MS, Ridgeway BM, Leung AY, Gerayli A, Yaksh $T L$. Concentration-effect relationship of intravenous lidocaine on the allodinia of complex regional pain syndrome types I and II. Anesthesiology 2000; 92: 75-83.

12 Kart T, Walther-Larsen S, Svejborg TF, Feilberg V,
Eriksen K, Rasmussen M. Comparison of continuous epidural infusion of fentanyl and bupivacaine with intermittent epidural administration of morphine for postoperative pain management in children. Acta Anaesthesiol Scand 1997; 41: 461-5.

13 Montes A, Warner W, Puig MM. Use of intravenous patient-controlled analgesia for the documentation of synergy between tramadol and metamizol. Br J Anaesth 2000; 85: 217-23.

14 Wood CE, Goresky GV, Klassen KA, Kuwahara B, Neil $S G$. Complications of continuous epidural infusions for postoperative analgesia in children. Can J Anaesth. 1994; 41: 613-20.

15 Mather LE, Cousins MJ. Local anaesthetics and their current clinical use. Drugs 1979; 18: 185-205.

16 Pentrell JM, Holder K, Gregory M. Plasma bupivacaine concentrations associated with continuous extradural infusions in babies. Br J Anaesth 1997; 78: 160-2. 